\title{
Odontosia patricia (Lepidoptera: Notodontidae) New to Korea, with Comment on the Notodontid Fauna of High Altitude of Jirisan Mt.
}

\author{
Sei-Woong Choi* \\ Department of Environmental Education, Mokpo National University, \\ Muan, Jeonnam 534-729, Korea
}

\begin{abstract}
We report a species of Notodontidae, Odontosia patricia Stichel 1918 for the first time from Korea. Two males of O. patricia were collected at the end of May, 2008 from Quercus mongolica forest of Jirisan Mt., a Korea Long-Term Ecological Research site. The notodontid-moth fauna and population changes of three years (2005-2007) from Q. mongolica forest site are provided.
\end{abstract}

Key words: Notodontidae, Odontosia, Lepidoptera, taxonomy, fauna, Korea

\section{INTRODUCTION}

Moths of Notodontidae are medium to large-sized moths, comprising about 2,500-3,000 species worldwide (Scoble, 1992). They can be easily recognized by the large and triangular forewing with a large prominent "tooth" on posterior margin and long abdomen. This prominent "tooth" of forewing produces a tuft that breaks the insect's outline and aids crypsis while the moth is at rest (Miller, 1991; Park and Kwon, 2001). The monophyly of the Notodontidae is well supported by the serrated edges on the tips of the tibial spurs and a teardrop-shaped, swollen area (bulla) of the metascutal region above the tympanum (Miller, 1991; Scoble, 1992).

Park et al. (1999) and Park and Kwon (2001) revised the notodontid species of Korea and recognized a total of 102 species. Recently Park et al. (2006) reported a subtropical notodontid species, Dudusa nobilis Walker from an island on Yellow sea, but the distribution of the species in Korean fauna is ambiguous.

Since 2005, a network of Korea Long-term Ecological Research (KLTER) has been established, sponsored by the Ministry of Environment. Jirisan Mt. was included as one of the terrestrial ecosystem monitoring sites of KLTER. Jirisan Mt. comprised two high altitude sites above 1,300 m, Quercus mongolica forest and Abies koreana forest and one pine forest at colline zone (302 $\mathrm{m}$ above sea level). Moths were collected monthly during May to October with a 22-watt Ultraviolet light trap.

During the course of this study in 2008, we collected a previously unrecorded species, Odontosia patricia Stichel for the first time from the Korean peninsula. The aim of the

\footnotetext{
*To whom correspondence should be addressed

Tel: 82-61-450-2783, Fax: 82-61-453-4843

E-mail: choisw@mokpo.ac.kr
}

present study was to provide the taxonomic information of $O$. patricia and annotated checklist of notodontid moth species of $Q$. mongolica forest site based on the last three-year monitoring project.

Examination of adults including male genitalia refers to Scoble (1992). Abbreviations are as follows: JN: Province Jeollanam-do, MNU: Mokpo National University.

\section{SYSTEMATIC ACCOUNTS}

Order Lepidoptera Linnaeus, 1758

Family Notodontidae, Stephens, 1829

Genus Odontosia Hübner, 1819

Odontosia Hübner, 1819: 145. Type species: Phalaena carmelita Esper

Diagnosis. The members of the genus can be distinguished by the bipectinate male antennae, short labial palpi, vestigial proboscis, thorax with dense woolly hair and scales, and broad wings with thinly scaled forewing with almost straight costal margin, pointed apex and strongly oblique dentate outer margin and hindwing with dentate distal margin and angular abdominal angle (Grünberg, 1912). They are similar to those of Lophontosia Staudinger in the dorsally tapering central fascia of forewing and dentate distal margin of wings. However, these two genera can be distinguished by the wing ground color and male and female genitalia. The male genitalia are characterized by the relatively short and hooked uncus and a pair of digitate gnathos, long slender membranous valva with medially expanded and a sclerotized harpe and broad, shallow saccus. The male genitalia of Odontosia can be distinguished from those of Lophontosia by the relatively long and well-developed gnathos and broad saccus without medial projection. The female genitalia can be dis- 


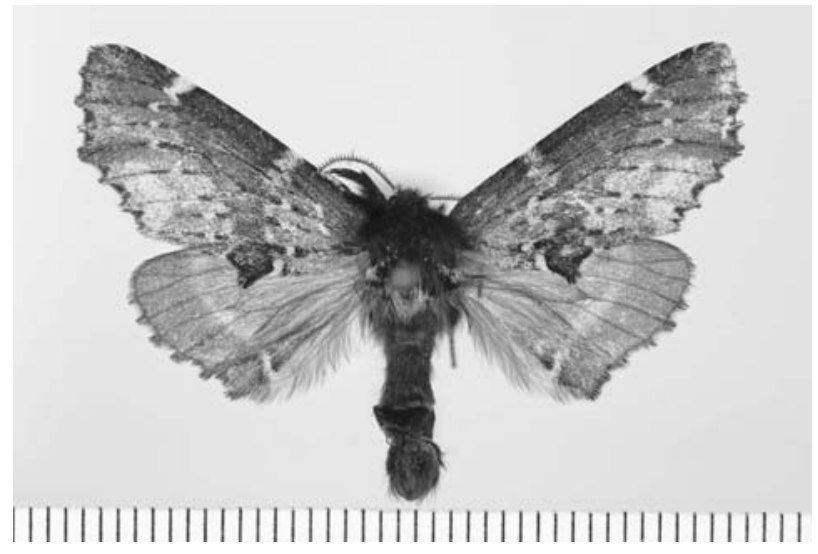

Fig. 1. Adult of Odontosia patricia. Scale bar=1 mm.

tinguished by the simple ostium bursae, the long sclerotized ductus bursae, and the large ovate corpus bursae with a patch of signa.

$1 *$ Odontosia patricia Stichel (Figs. 1, 2A, B, C)

Odontosia patricia Stichel, 1918: 38, pl. 1:20. (TL: Vladivostok)

Materials examined. [JN] $20^{7}$ Jirisan Mt., JN: Gurye, E $127^{\circ}$ 33', N 35 18', 1,371 m, 22 May 2008. coll. MNU.

Diagnosis. This species (wingspan $38 \mathrm{~mm}$ ) can be distinguished by the larger wingspan, the shortly pectinate male antennae, short labial palpi, long and brown hairy thorax and legs, and the dorsally shrunk central fascia with dentate postmedial line of dark brownish forewing. This species is externally similar to a sympatric species, $O$. sieversii (Ménétriès) in the shape of wings, but can be distinguished by the yellowish white postmedial lines of forewing and darker wing ground color. Eighth sternum of male abdomen has a large and broad posterior process (Fig. 2A). The male genitalia can be diagnosed by the relatively short hooked uncus, a pair of digitate gnathos, the slender membranous valva with dorsally expanded and a strongly sclerotized digitate harpe and slender aedeagus with three patches of spinular cornuti. The male genitalia of $O$. patricia can be distinguished from those of $O$. sieversii by the less developed costa, larger cucullus and relatively short harpe of valva (Daniel, 1964; Schintlmeister, 1987).

Distribution. Korea, Japan, Russian Far East.

\section{Notodontid-moth fauna in Quercus mongolica forest site of Jirisan Mt.}

Three-year monitoring (2005-2007) of Quercus mongolica
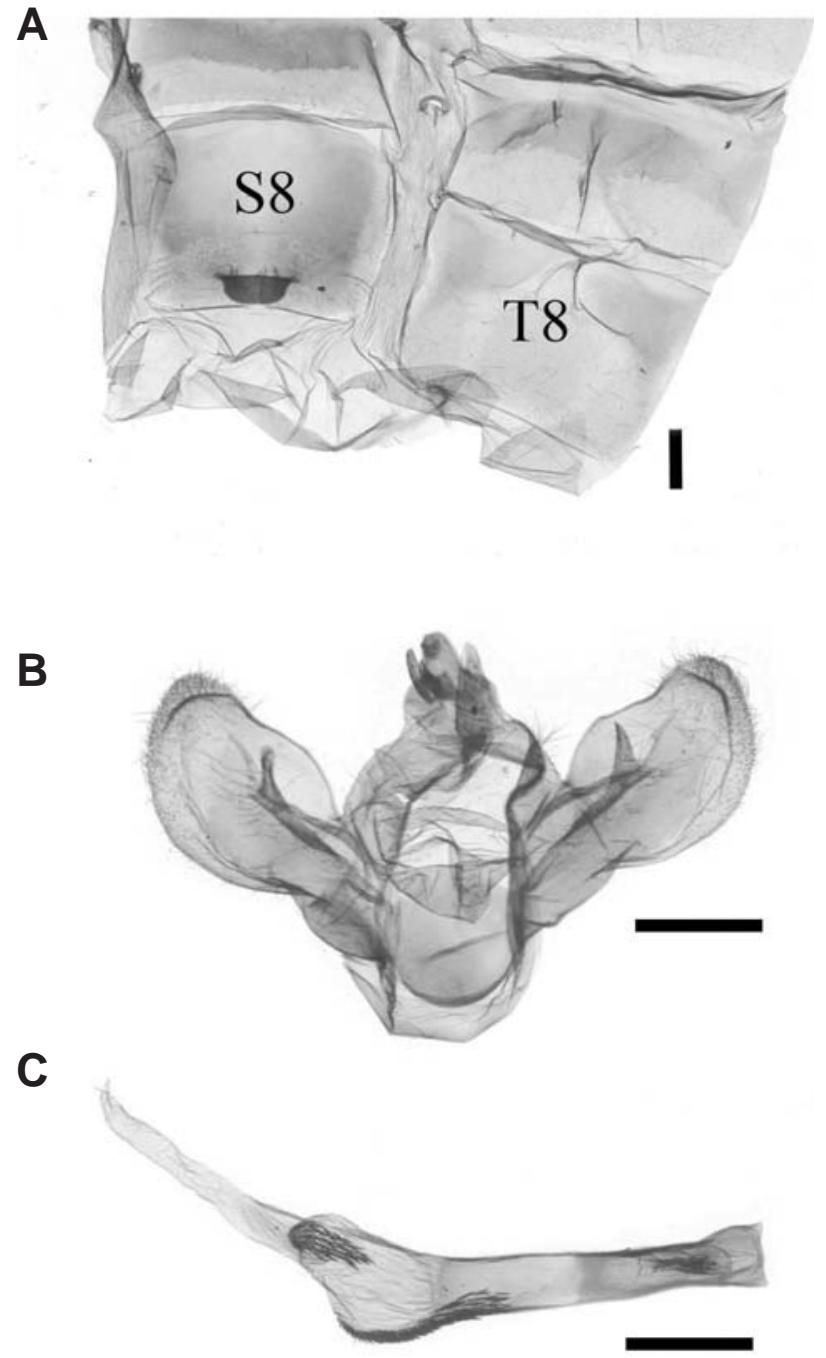

Fig. 2. Male abdomen and genitalia of Odontosia patricia. A, abdomen, T8. tergum 8 , S8, sternum 8 ; B, male genital capsule; $C$, aedeagus with everted vesica. Scale bars $=1 \mathrm{~mm}$.

forest site found 11 genera and 12 species of Notodontidae (Fig. 3). Drymonia dodonides Staudinger was the dominant species with 62 individuals and followed by Peridea gigantea Butler and Neodrymonia delia (Leech). It was shown that species richness and abundance differed in each year: 3 species and 5 individuals in 2005, 6 species and 28 individuals in 2006 and 9 species and 68 individuals in 2007. Two species (D. dodonides, and P. gigantea, 16.7\%) were caught during the last three years, another two species $(N$. delia, Fentonia ocypete (Bremer), 16.7\%) were caught in two years (2006 and 2007), and the remaining 8 species (66.7\%) were caught once in three years. Estimated species richness of Chao 1 (Colwell, 2005) based on three-year sampling sug-

\footnotetext{
1*톱니띠재주나방 (신칭)
} 


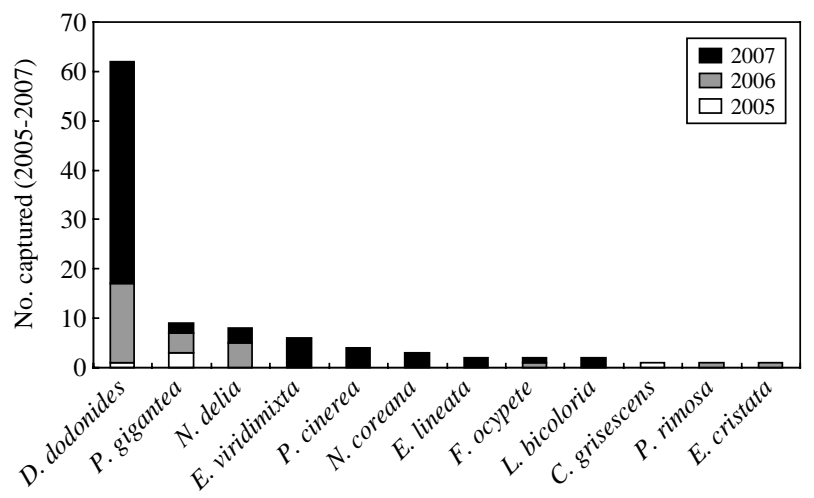

Fig. 3. List of notodontid species by the number of total catches (2005-2007). Abbreviations of species. D. dodonides: Drymonia dodonides, P. gigantea: Peridea gigantea, N. delia: Neodrymonia delia, E. viridimixta: Ellida viridimixta, P. cinerea: Pheosiopsis cinerea, E. lineata: Epodonta lineata, F. ocypete: Fentonia ocypete, L. bicoloria: Leucodonta bicoloria, C. grisescens: Cnethodonta grisescens, P. rimosa: Pheosia rimosa, and E. cristata: Euhampsonia cristata.

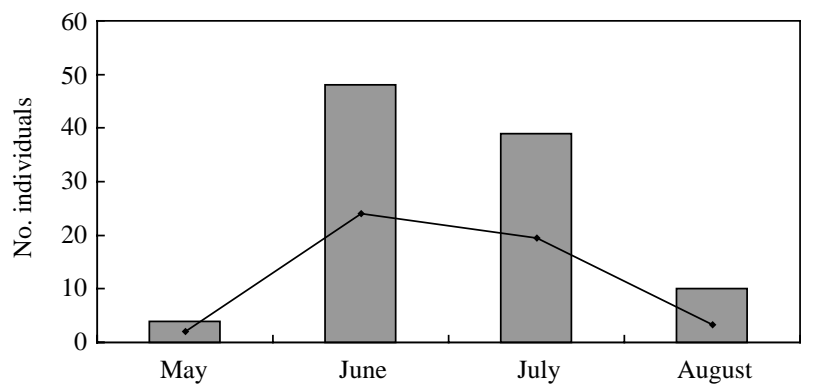

Fig. 4. Monthly catches of notodontid moths in Quercus mongolica forest site of Jirisan Mt. from 2005 to 2007. Line indicates mean number of total catches and bars indicate accumulated number of catches for three years.

gested $12.75( \pm 1.42)$ species. Monthly catches of moths showed that they were flying from the end of May to August with the highest peak in June (Fig. 4). Host plants of the recorded notodontid moths in Quercus mongolica forest site showed that half of them were Quercus-feeders, suggesting a positive relationship between adult catches and forest type.

\section{Annotated Checklist of Notodontidae species in Quercus mongolica forest site of Jirisan Mt.}

Subfamily Cerurinae

\section{Cnethodonta grisescens Staudinger, 1887}

Date collected. 13 Aug. 2005 (1 ex.)

Host plants: Salicaceae: Salix koreensis, Ulmus propinqua (Park and Kwon, 2001).
Subfamily Notodontinae

Drymonia dodonides Staudinger, 1887

Date collected. 4 Jun. 2005 (1 ex), 20 Jun. 2006 (6 exx), 25 Jul. 2006 (6 exx), 13 Aug. 2006 (4 exx), 26 May 2007 (3 exx), 20 Jun. 2007 (31 exx), 20 Jul. 2007 (11 exx)

Host plants: Fagaceae: Quercus dentata, Q. aliena, Q. myrsinaefolia, Q. mongolica, Betulaceae: Betula platyphylla var. japonica (Park and Kwon, 2001).

\section{Ellida viridimixta (Bremer, 1861)}

Date collected. 20 Jun. 2007 (1 ex), 20 Jul. 2007 (5 exx)

Host plants: Fagaceae: Quercus mongolica, Ulmaceae: Zelkova serrata (Park and Kwon, 2001).

\section{Epodonta lineata (Oberthür, 1880)}

Date collected. 20 Jun. 2007 (2 exx)

Host plants: Araliaceae: Kalopanax septemlobus (Sugi, 1987).

\section{Euhampsonia cristata (Butler, 1877)}

Date collected. 25 Jul. 2006 (1 ex)

Host plants: Fagaceae: Quercus serrata, Q. myrsinaefolia, Q. acutissima, Q. mongolica (Park and Kwon, 2001).

\section{Fentonia ocypete (Bremer, 1861)}

Date collected. 25 Jul. 2006 (1 ex), 20 Jul. 2007 (1 ex)

Host plants: Fagaceae: Quercus serrata, Q. myrsinaefolia, $Q$. acutissima, Q. dentata, Q. mongolica, Castanea crenata (Park and Kwon, 2001).

Leucodonta bicoloria (Denis and Schiffermüller, 1775) Date collected. 20 Jun. 2007 (1 ex), 20 Jul. 2007 (1 ex)

Host plants: Betulaceae: Betula patyphylla var. japonica, $B$. daurica (Park and Kwon, 2001).

\section{Neodrymonia coreana Matsumura, 1922}

Date collected. 20 Jul. 2007 (3 exx)

Host plants: Symplocaceae: Symplocos chinensis for. pilosa (Sugi, 1987).

\section{Neodrymonia delia (Leech, 1889)}

Date collected. 20 Jun. 2006 (2 exx), 25 Jul. 2006 (3 exx), 20 Jul. 2007 (3 exx)

Host plants: Symplocaceae: Symplocos chinensis for. pilosa (Sugi, 1987).

\section{Peridea gigantea Butler, 1877}

Date collected. 13 Jul. 2005 (3), 20 Jun. 2006 (1 ex), 25 Jul. 2006 (2 exx), 13 Aug. 2006 (1 ex), 20 Jul. 2007 (1 ex), 20 Aug. 2007 (1 ex)

Host plants: Fagaceae: Quercus serrata, Q. acutissima, $Q$. 
grosseserrata, Castanea crenata (Park and Kwon, 2001).

\section{Pheosia rimosa Packard, 1864}

Date collected. 25 Jul. 2006 (1 ex)

Host plants: Salicaceae: Populus maximowizii, P. davidiana

(Park and Kwon, 2001).

\section{Pheosiopsis (Suzukiana) cinerea ussuriensis (Moltrecht, 1914)}

Date collected. 20 Jun. 2007 (4 exx)

Host plants: Fagaceae: Quercus serrata, Q. crispula (Sugi, 1987).

\section{ACKNOWLEDGEMENTS}

I would like to thank Messrs. Jeong-Seop An, Sun-Gyun Kim, Dong-Ho Kim, Jun-Ho Kim, Chul-Gi Lee and Miss Marana Park for sampling and identifying specimens. This work was supported by Korea National Long-Term Ecological Research from Ministry of Environment and the research fund from Mokpo National University, Korea.

\section{REFERENCES}

Colwell, R.K., 2005. EstimateS: Statistical estimation of species richness and shared species from samples. Version 7.5. User's Guide and application published at: http://purl.oclc. org/estimates.

Daniel, F., 1964. Odontosia sieversi Mén. und patricia Stich. (Lep.-Notodontidae). Z. Wiener Entomol. Ges., 49: 37-47.

Grünberg, K., 1912. Family Notodontidae. In Seitz, A., ed., The
Macrolepidoptera of the World. Division I: Palaearctics, Volume II. Bombyces and Sphinges, Verlag des Seitzschen Werkes, Stuttgart, pp. 305-306.

Hübner, J., 1819. Verzeichniss bekannter Schmettlinge. Vol. 10. Bey dem Verfasser zu Finden, Augsburg, p. 145.

Miller, J.S., 1991. Cladistics and classification of the Notodontidae (Lepidoptera: Noctuioidea) based on larval and adult morphology. Bull. Amer. Mus. Nat. Hist., 204: 1-230.

Park, K.T. and Y.D. Kwon, 2001. Superfamily Bombycoidea and family Notodontidae. Economic insects of Korea 7. Ins. Koreana Suppl., 14: 43-147.

Park, K.T., S.S. Kim, Yu. A. Tshistjakov and Y.D. Kwon, 1999. Illustrated Catalogue of Moths in Korea (I). In Park, K.T., ed., Insects of Korea, Series 4, KRIBB and Center for Insect Systematics, Korea, pp. 179-335.

Park, K.T., T.M. Kang, M.Y. Kim, M.Y. Chae, E.M. Ji and Y.S. Bae, 2006. Discovery of the ten species of subtropical moths in Is. Daecheong, Korea. Korean J. Appl. Entomol., 45: 261-268.

Schintlmeister, A., 1987. Untersuchungen zur Systematik und Zoogeographie der europäischen und nordafrikanischen Zahnspinner unter Berücksichtigung ihrer nächsten Verwandten (Lepidoptera: Notodontidae). Ph.D. Dissertation of Humboldt University zu Berlin, 96 p. +49 pls.

Scoble, M.J., 1992. The Lepidoptera, form, function and diversity. Oxford University Press, Oxford, 404 p. +4 pls.

Stichel, H., 1918. Zur Monographie der Odontosia sieversi (Mén.) sowie Beschreibung einer neuen verwandten Art. Ztschr. wiss. Ins. Biol., 14: 25-38.

Sugi, S. (ed.), 1987. Larvae of larger moths in Japan. Kodansha, Japan, p. 301 (In Japanese with English summary).

Received October 15, 2008 Accepted November 7, 2008 